\title{
DIMENSÕES ESSENCIAIS DAS BIBLIOTECAS PÚBLICAS
}

\author{
Marina Nogueira Ferraz \\ Doutoranda em Ciência da Informação \\ Universidade Federal de Minas Gerais \\ marina.nogueiraf@gmail.com
}

Ligia Maria Moreira Dumont

Doutora em Ciência da Informação Universidade Federal de Minas Gerais dumont@eci.ufmg.br

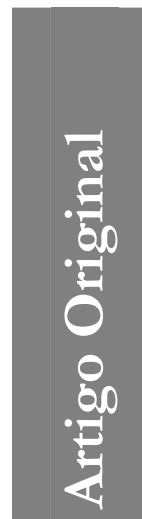

\section{Resumo}

A partir de uma reflexão teórica acerca do papel social das bibliotecas públicas, o presente artigo apresenta doze dimensões essenciais para se pensar sua atuação junto às comunidades em que estão inseridas, demonstrando sua relevância para a participação democrática e cidadã. Discute a importância da atuação do profissional bibliotecário como agente fundamental para a interlocução com a comunidade, para o contato com a leitura e a informação e, consequentemente, para o estabelecimento de relações pessoais, profissionais e afetivas na biblioteca.

\section{Palavras-chave}

Bibliotecas públicas. Papel social. Atuação do bibliotecário.

\section{INTRODUÇÃO}

A quinta lei da Biblioteconomia proposta pelo pesquisador indiano Ranganathan (2009) diz que a biblioteca é um organismo vivo. Nessa perspectiva, ao se refletir sobre o papel social das bibliotecas públicas é possível pensar que essa faceta sofre a influência do tempo histórico, das condições econômicas, sociais e culturais do contexto em que estão inseridas, e como ainda não houve fenômeno epistemológico que quebrasse tal paradigma, esta lei ainda se faz válida.

Considerando que as bibliotecas públicas na primeira década nos anos 2000, precisaram se reinventar tendo em vista as demandas advindas da Sociedade da Informação, tais como acesso às novas tecnologias, disseminação seletiva da informação e toda a urgência que acompanha estes processos, hoje esse cenário ainda parece ser desafiador para a maioria das bibliotecas públicas brasileiras. Somam-se outras demandas sociais que acabam por afetar a atuação das bibliotecas, como o auxílio no combate à violência em cenários urbanos e zonas rurais, a desinformação que gera ameaças à democracia brasileira, ou ainda a dificuldade de acesso aos dados públicos, mesmo com a existência da Lei de Acesso à Informação. Todos esses problemas, que se mostram de diferentes modos, interferem e influenciam a atuação das bibliotecas públicas. Segundo Machado, Elias Junior e Achilles (2014), para pensar a biblioteca pública no contexto da sociedade da informação é preciso considerar os,

[...] elementos constituintes dessa configuração social, política, econômica e cultural, ou seja, é refletir sobre os processos relativos ao universo dessas bibliotecas no que tange sua missão, função, organização e administração. Ademais, as- 
sociar a biblioteca pública ao espaço público significa antes de tudo, pensar esse espaço como um lugar que não se configura como um espaço institucional privado, estático ou simplesmente delimitado pelo Estado, mas sim, um espaço de sentido, de sociabilidade, dinâmico, fluido, compartilhado, que se constrói a partir de ações coletivas (MACHADO; ELIAS JUNIOR; ACHILLES, 2014, p. 124).

Este artigo ${ }^{1}$ pretende demonstrar, baseado na literatura concernente à área de bibliotecas públicas, algumas dimensões essenciais para se pensar seu papel social. Com foco nas potencialidades da biblioteca pública para a construção de uma atuação relevante social e politicamente, optamos por apontar os aspectos que promovem este lugar de representatividade, muito embora em nenhum momento é possível descuidarse da situação penosa que vive a maioria das bibliotecas públicas brasileiras. Esse foi o viés de discussão eleito para tentar superar o lugar do discurso de "muro de lamentações" ocupado pelas bibliotecas públicas, e pensar possíveis alternativas de atuação para que elas se fortaleçam e repensem seu caminho, corrigindo sua rota rumo a um lugar que, oxalá, faça a diferença para as comunidades onde estão inseridas.

\section{AS BIBLIOTECAS PÚBLICAS E SEU PAPEL SOCIAL}

Para iniciar a exposição sobre as bibliotecas públicas e seu papel social, abordaremos seu conceito, de forma que haja um entendimento base para as discussões posteriores.

Em 1994 a Federação Internacional de Associação de Bibliotecários e Bibliotecas $^{2}$ (IFLA), organismo internacional que representa os interesses dos serviços bibliotecários, reconhecida mundialmente

1 Este artigo é parte integrante de pesquisa de doutoramento do Programa de Pós-Graduação em Ciência da Informação da UFMG.

2 International Federation of Library Associations and Institutions. como referência para a área, publicou, em conjunto com a Organização das Nações Unidas para a Educação, a Ciência e a Cultura $^{3}$ (UNESCO) o Manifesto IFLA/UNESCO (1994) para a biblioteca pública. Tal manifesto, que foi uma evolução do Manifesto de Caracas (UNITED NATIONS EDUCATIONAL, SCIENTIFIC AND CULTURAL ORGANIZATION, 1985), tornou-se referência para a área, e continua a ser citado em diversas publicações, definindo assim a biblioteca pública.

A biblioteca pública é o centro local de informação, tornando prontamente acessíveis aos seus utilizadores o conhecimento e a informação de todos os gêneros. Os serviços da biblioteca pública devem ser oferecidos com base na igualdade de acesso para todos, sem distinção de idade, raça, sexo, religião, nacionalidade, língua ou condição social. Serviços e materiais específicos devem ser postos à disposição dos utilizadores que, por qualquer razão, não possam usar os serviços e os materiais correntes como, por exemplo, minorias linguísticas, pessoas deficientes, hospitalizadas ou reclusas.

Todos os grupos etários devem encontrar documentos adequados às suas necessidades. As coleções e serviços devem incluir todos os tipos de suporte e tecnologias modernas apropriadas assim como materiais tradicionais. É essencial que sejam de elevada qualidade e adequadas às necessidades e condições locais. As coleções devem refletir as tendências atuais $\mathrm{e}$ a evolução da sociedade, bem como a memória da humanidade e o produto da sua imaginação.

As coleções e os serviços devem ser isentos de qualquer forma de censura ideológica, política ou religiosa e de pressões comerciais (UNITED

NATIONS

\footnotetext{
${ }^{3}$ United Nations Educational, Scientific and Cultural Organization.
} 


\section{EDUCATIONAL, SCIENTIFIC AND CULTURAL ORGANIZATION, 1994, p. 1).}

O caráter generalista, democrático e diverso das bibliotecas públicas fica claro nessa definição, exaltando a diversidade de públicos, serviços e acervos. A finalidade da biblioteca pública, explicitada em outra publicação da International Federation of Library Associations and Institutions, (2012, p. 2), avança nesta definição, uma vez que entende a instituição como a que "desempenha importante papel no desenvolvimento e preservação de uma sociedade democrática ao oferecer ao cidadão o acesso a uma ampla e diversificada variedade de conhecimentos, ideias e opiniões".

Nota-se que seu conceito e sua finalidade apontam para um importante papel social a ser desempenhado nas comunidades e que se apresenta em diferentes dimensões. No entanto, apesar das orientações da IFLA serem um marco para as bibliotecas públicas, a realidade parece bem mais cruel com relação à qualidade dos acervos e serviços prestados, e na visão pessimista de Milanesi (2013), elas ainda vivem no século XIX.

O professor David Lankes, da Universidade de Syracuse nos Estados Unidos, publicou em 2012 o livro Expect More: melhores Bibliotecas para um mundo complexo, publicado em português em 2016, no qual propõe uma nova visão e atuação para as bibliotecas, incluindo as públicas, mostrando seu potencial de inovação de atuação, impactando positivamente no desenvolvimento das comunidades onde estão inseridas, sob o argumento de que necessitamos de melhores bibliotecas.

Em uma cidade ou numa das 500 melhores companhias eleitas pela Fortune, a biblioteca deve moldarse ao contexto e adotar os mesmos objetivos. Se a sua comunidade se esforçar para crescer, a biblioteca também precisa crescer. Se você se preocupa com o futuro, ou com a economia, ou com o futuro da democracia em seu país, sua bibliote- ca também deve se preocupar. Se você torna pública estas preocupações, se prepara com o possível e com o impossível, então a biblioteca e bibliotecários podem abraçar estes ideais e objetivos (LANKES4, 2016).

Outro documento importante recentemente publicado pela IFLA, com o título de Acesso e oportunidade para todos: como as bibliotecas contribuem para a agenda de 2030 das Nacões Unidas (INTERNATIONAL FEDERATION OF LIBRARY ASSOCIATIONS AND INSTITUTIONS, 2017), destaca a importância das bibliotecas para cumprir os objetivos de desenvolvimento sustentável, uma vez que:

O acesso público à informação permite que as pessoas tomem decisões conscientes que podem melhorar suas vidas. As comunidades que têm acesso à informação relevante e no tempo certo estão melhor posicionadas para erradicar a pobreza e a desigualdade, melhorar a agricultura, proporcionar educação de qualidade e promover a saúde, a cultura, a pesquisa e a inovação (INTERNATIONAL

FEDERATION OF LIBRARY ASSOCIATIONS AND INSTITUTIONS, 2017).

Algumas dimensões das bibliotecas públicas serão abordadas a seguir, com a intenção de demonstrar a importância delas para a criação e manutenção de sociedades mais justas e igualitárias, contribuindo para o avanço das pesquisas na área de bibliotecas públicas. Foram elaboradas doze (12) categorias que versam sobre temas como acervo, serviços e características de atuação, que são essenciais para pensar seu papel social e sua atuação nas comunidades.

\footnotetext{
4 A tradução do livro para o português ocorreu a partir de 2015 e foi disponibilizada pela internet, divida em capítulos, portanto, as páginas não se encontram numeradas.
} 
Quadro 1 - Dimensões essenciais das bibliotecas públicas

\begin{tabular}{|c|l|l|l|}
\hline \multicolumn{4}{|c|}{ Dimensões fundamentais } \\
\hline 1 & Acervo & 7 & $\begin{array}{l}\text { Acesso às tecnolo- } \\
\text { gias }\end{array}$ \\
\hline 2 & Serviços & 8 & $\begin{array}{l}\text { Conhecimento das } \\
\text { comunidades }\end{array}$ \\
\hline 3 & Incentivo à leitura & 9 & $\begin{array}{l}\text { Interlocução com a } \\
\text { comunidade }\end{array}$ \\
\hline 4 & $\begin{array}{l}\text { Preservação da me- } \\
\text { mória local e ação } \\
\text { cultural }\end{array}$ & 10 & Lugar de encontro \\
\hline 5 & $\begin{array}{l}\text { Informação à comu- } \\
\text { nidade }\end{array}$ & 11 & $\begin{array}{l}\text { Construção da } \\
\text { cidadania }\end{array}$ \\
\hline 6 & $\begin{array}{l}\text { Lugar de aprendizado } \\
\text { ao longo da vida }\end{array}$ & 12 & $\begin{array}{l}\text { Perfil do bibliotecá- } \\
\text { rio }\end{array}$ \\
\hline
\end{tabular}

Fonte: Elaborado pelas autoras, 2018.

\subsection{Acervo}

O caráter social das bibliotecas públicas se inicia em suas portas abertas para a rua, mas também em seu acervo, pois é nele que se encontra a informação em diversos suportes, possibilitando contemplar a população em suas necessidades e gostos e também em suas demandas ainda não identificadas, mas que é seu papel fomentá-las. Nesse sentido, "a biblioteca pública deve atuar como órgão social, de modo a propiciar material bibliográfico sobre todos os assuntos e de todas as linhas de pensamento [...]" (ARAÚJO, 1985, p.110).

A variedade de suportes e temas foi abordada por Santa Maria (2011):

Em uma biblioteca se oferece a todos os visitantes e usuários oportunidades de leitura, de aprendizagem e de informação, colocando à livre disposição materiais em diferentes mídias e formatos: livros de literatura, histórias em quadrinhos, obras de ciência e tecnologia, acesso à internet, conferências, exposições, filmes, bases de dados, livros de referência, revistas, jornais, música, informações sobre a área, entre outros (SANTA MARIA, 2011, p. 11, tradução nossa).
Para Pérez Iglesias (1999), o livre acesso que a biblioteca pública proporciona favorece a permanência de diversos grupos e dá a oportunidade de vivenciar o acervo em sua variedade, contribuindo para atitudes criativas.

Essa bênção chamada "livre acesso" podemos navegar, ler à toa, passando de um título para outro e de assunto para outro em um processo não-instrumental, mas criativo, que nos tira da pressa e tem muito a ver com essa sensação de paz e relaxamento que muitos usuários valorizam como uma das principais qualidades de bibliotecas (PÉREZ IGLESIAS, 1999, p. 26, tradução nossa).

Bem mais que os clássicos da literatura universal, a biblioteca pública precisa contemplar os gostos e desejos da população, para além de suas necessidades explicitadas. Vergueiro (2010, p. 13) aponta a importância de se considerar as características do usuário real ou potencial para a definição do material que será incorporado ao acervo, pois esta questão envolve um "conhecimento aprofundado dos usuários, suas características e preferências". Essa diversidade precisa ser constantemente atualizada e, preferencialmente, isenta de gostos, ideologias dos que fazem a seleção do acervo, além de pressões dos governos e administrações. Essa é uma das características mais valorosas da biblioteca pública, na medida em que atende a diferentes grupos da população e sua coleção deve refletir esta diversidade, na medida em que oferece diferentes suportes, formatos, gêneros e títulos (SANTA MARIA,2011).

\subsection{Serviços}

O serviço de empréstimo domiciliar é um dos mais frequentes nas bibliotecas públicas, estando presente desde o início de sua história. No entanto, oferece também outros tipos de serviço para suprir as necessidades de uma comunidade. 
Nesse processo de globalização, de novos paradigmas tecnológicos e sociais e do modelo de desenvolvimento sustentável, caberá à biblioteca pública trabalhar no sentido de corrigir as deficiências do passado, como criar uma interação adequada com a comunidade e implantar produtos que de fato facilitem o acesso à Sociedade da Informação (SUAIDEN, 2000, p. 57).

A oferta desses serviços deve perpassar pela satisfação das necessidades informacionais, estando atenta para mudanças da sociedade, pois "com a oferta de serviços, a biblioteca pública procura atender às necessidades de informação e leitura da comunidade e atrair aqueles que não frequentam a biblioteca" (SANTA MARIA, 2011, p. 50, tradução nossa).

As diretrizes da IFLA para as bibliotecas públicas atentam para a importância da instituição resistir às pressões externas e de seus serviços estarem sempre alinhados às necessidade da comunidade atendida.

Os serviços da biblioteca pública não devem sujeitar-se a qualquer forma de pressão ideológica, política, religiosa ou comercial. É preciso que esses serviços possam se adaptar e desenvolver de modo a refletir as mudanças na sociedade, como, por exemplo, variações nas estruturas familiares, padrões de emprego, alterações demográficas, diversidade cultural e métodos de comunicação (INTERNATIONAL FEDERATION OF LIBRARY ASSOCIATIONS AND INSTITUTIONS, 2012, p. 42).

Este é um desafio para as bibliotecas públicas, pois uma vez que são mantidas pelo poder público, não é raro que sofra pressão política para constituição de serviços e acervos, especialmente em locais onde não há uma política pública de Estado para a área.

\subsection{Incentivo à leitura}

$\mathrm{O}$ incentivo à leitura se configura como um serviço primordial das bibliotecas públicas, uma vez que o acesso à informação na sociedade está consolidado pela letra registrada. Percebe-se que, na maioria as bibliotecas, essas ações de incentivo à leitura são voltadas para as crianças. No entanto, esta atividade deve voltar seu olhar para todos os públicos que a frequentam.

Seria conveniente que as bibliotecas públicas desenvolvessem programas motivadores da leitura entre os diferentes segmentos da sociedade, especialmente para os leitores relutantes e cujo nível de autonomia do comportamento de ler seja baixo (ARAÚJO, 1985, p. 109).

Essa diversidade de público e a necessidade de se contemplar todos eles com ações de incentivo à leitura também foi alertada por Santa Maria (2011).

A promoção da leitura não se limita às atividades com as crianças. Outros públicos da Biblioteca como os jovens, mães, adultos, idosos, pessoas reclusas em prisões e hospitais, todos a partir do nascimento até a velhice podem se beneficiar de tais programas (SANTA MARIA, 2011, p. 57, tradução nossa).

O papel social da leitura ganha relevância quando se considera que a leitura é:

Um dos meios mais eficazes para a expansão do pensamento crítico e de acesso à cultura e aquisição de experiências [...] bem como a possibilidade de melhor posicionamento crítico e tomada de decisões, assegurando, assim, sua maior participação na sociedade (ARAÚJO, 1985, p. 116).

Os programas de incentivo à leitura, assim como todos os serviços oferecidos 
pelas bibliotecas públicas, sofrem a influência das características da sociedade em que estão inseridos. E ainda que existam características que homogeneízem os sujeitos, a experiência leitora é particular e subjetiva. Dumont (2001) discute esse assunto.

Os paradigmas da leitura, válidos para uma comunidade de leitores, num momento e num lugar determinados, comportam modos específicos. A sua caracterização é, portanto, indispensável a toda abordagem que vise reconstruir o modo como os textos podem ser apreendidos. Torna-se imprescindível lembrar que essas singularidades não advêm necessariamente de uma homogeneidade: são pessoas bem diferentes que se assemelham porque são obrigadas a pertencer a uma classe [...]. Porém, o real sentimento de pertencer a uma comunidade - os companheiros, a cidade, a turma - não destrói, não elimina as diferenças de sensibilidade, de sistemas de valores (DUMONT, 2001, p. 47).

Lankes (2016) também alerta que a biblioteca pública, por ser um local democrático de leitura, deve permitir as pessoas lerem o que for de sua escolha e que não é papel da biblioteca dizer o que deve ou não ser lido.

O incentivo à leitura é um trabalho constante e importante nas bibliotecas públicas e para muitos sujeitos pode ser a única oportunidade de ser inserido na cultura letrada. A biblioteca pública não está sozinha na cadeia de formação de leitores, que conta também com a família e com as bibliotecas escolares. No entanto, ao considerar uma família não leitora, além da deficiência de grande parte das bibliotecas escolares, a biblioteca pública se coloca como a principal responsável por este papel.

\subsection{Preservação da memória local e ação cultural}

Para se discutir a biblioteca pública como lugar de preservação da memória local é preciso pensar na ideia de memória como uma possibilidade de reelaboração da experiência da vida humana na medida em que reconhece e atualiza uma lembrança (SILVEIRA; REIS, 2011). Para Silveira e Reis (2011), a memória não é apenas um "decalque do passado", pois os acontecimentos não são lineares e cada lembrança é colorida com significados pessoais, fazendo da memória um terreno de incertezas. Ainda assim, o homem conseguiu criar sistemas de significação que dessem coerência à instabilidade da memória e consequentemente criou instituições que pudessem se ocupar da preservação da memória coletiva (SILVEIRA; REIS, 2011). Igrejas, museus escolas, arquivos e bibliotecas são exemplos de lugares de memória.

É o que acontece com as bibliotecas, especialmente com as públicas, cuja função social está diretamente ligada à missão de preservar, organizar e disseminar os elementos culturais e os saberes concebidos pela ação racional dos homens. Enquanto "lugares de memória”, as bibliotecas públicas tendem a reafirmar os saberes e a torná-los móveis, traduzíveis, permutáveis. São instituições que nos permitem acessar, por intermédio de seus acervos, as experiências comuns à toda humanidade, bem como as razões e os intentos de cada um de seus usuários em particular (SILVEIRA; REIS, 2011, p. 44).

A produção cultural e histórica da cidade encontra, neste espaço, um lugar de preservação e disseminação, uma vez que guarda a produção dos citadinos. Segundo a International Federation of Library Associations And Institutions (2012, p.19) "a biblioteca pública deve ser uma instituição indispensável para a comunidade local no 
que se refere à coleta, preservação e promoção da cultura local em toda a sua diversidade". Cesarino (2007) descreve os tipos de materiais que a biblioteca pública pode guardar, fortalecendo a preservação da memória.

Se a biblioteca pública municipal é também o centro de memória da cidade, dever ter em seu acervo obras que retratem a história local, obras literárias escritas por pessoas da comunidade, jornais, revistas, boletins, cartazes, objetos, fotos, depoimentos, cartas e outros documentos que retratam a história do município, seus benfeitores, de sua gente, de seu desenvolvimento e de suas raízes (CESARINO, 2007, p. 81).

Um dos objetivos das Nações Unidas para 2030 é tornar as cidades e os assentamentos humanos inclusivos, seguros, resilientes e sustentáveis. Nesse sentido, a IFLA entende que:

Bibliotecas desempenham um papel fundamental na preservação de um patrimônio cultural inestimável, em todas as suas formas, para as futuras gerações. A cultura fortalece as comunidades locais e favorece $\mathrm{O}$ desenvolvimento inclusivo e sustentável das cidades (INTERNATIONAL

FEDERATION OF LIBRARY ASSOCIATIONS AND INSTITUTIONS, 2017, p. 14).

As bibliotecas públicas são hoje o equipamento cultural mais presente em todo o Brasil, "mesmo com toda a precariedade que a falta de investimentos públicos locais impõem" (FERNANDEZ, 2016, p. 14). A função de ser o ponto central do desenvolvimento cultural das comunidades se enseja como um dos pilares de sua atuação.

A Biblioteca Pública, em seu verdadeiro sentido de atuação, livre, aberta, democrática, socializadora, que ao mesmo tempo em que cuida da preservação da memória investe na construção do conhecimento e soma esforços para que transforme e seja transformada para e pelo usuário, e que, em razão deste, possa se tornar um ambiente vivo e efervescente de cultura (BERNARDINO; SUAIDEN, 2011, p. 34).

As diversas manifestações artísticas, ao estarem presentes na biblioteca, dialogando com a cultura letrada, transformam-se em potencial transformador da sociedade, pois podem contribuir com a melhora da "qualidade de vida social mais do que outras, que se limitam a prestar serviços de depósito e empréstimo" (ARAÚJO, 1985, p. 109).

Torna-se função da biblioteca
pública apoiar e dar visibilidade às
manifestações culturais humanas "sem se
levar em consideração critérios ligados à
etnia, crença religiosa, condição financeira,
questões sexuais ou políticas, propiciando a
qualquer usuário amplo acesso aos vários
signos preservados em seus acervos"
(SILVEIRA; REIS, 2011, p. 39).

\subsection{Informação à comunidade}

Por ser uma instituição referência para as comunidades no que diz respeito à disseminação de informação de qualidade, as bibliotecas públicas desenvolvem um serviço de grande valia para a população: a informação utilitária. Pela característica de um público diversificado, diferentes pessoas precisam encontrar as informações de seu interesse. Segundo Vieira (2011), nas décadas de 1970 a 1990 o público alvo deste tipo de informação eram as pessoas de baixa renda. No entanto, a informação utilitária supre demandas informacionais de qualquer pessoa. Esse tipo de informação fortalece a construção da cidadania e o desenvolvimento pessoal, como demonstra Santa Maria (2011):

Serviço de informação local: O fornecimento de informações de caráter local e comunitário se 
relaciona com aspectos tais como saúde, habitação, impostos, direitos humanos, transportes, educação, procedimentos, cultura, recreação, turismo, etc. A biblioteca coleta essas informações, organiza e divulga para que os cidadãos conheçam os seus direitos e deveres e possam participar efetiva e democraticamente no futuro de sua comunidade (SANTA MARIA, 2011, p. 58, tradução nossa).

Suaiden (2008) vai mais além, colocando este serviço como o maior objetivo das bibliotecas públicas.

O serviço de informação à comunidade é o mais valioso instrumento de que dispõe a biblioteca pública para atender eficientemente seus usuários, e pode chegar a ser, sem dúvida, o meio mais eficaz de atração e conquista de usuários, logrando assim seu principal objetivo: o serviço à comunidade (SUAIDEN, 2008, p. 80).

No documento da IFLA de 2017, no objetivo de assegurar a disponibilidade da água e saneamento para todos e também assegurar o acesso confiável, sustentável, moderno e a preço acessível de energia para todos propostos pelas Nações Unidas, as bibliotecas podem contribuir na medida em que:

Oferecem o acesso público à informação sobre água, uso da energia e saneamento. Muitas bibliotecas públicas e comunitárias de todo o mundo são o único lugar onde as pessoas têm acesso confiável a eletricidade para ler, estudar e candidatar-se e um emprego (INTERNATIONAL FEDERATION OF LIBRARY ASSOCIATIONS AND INSTITUTIONS, 2017, p. 10).

\subsection{Lugar do aprendizado ao longo da vida}

Para aqueles que estão vinculados a uma escola e principalmente para os que não estão, a biblioteca pública configura-se como a principal porta de acesso à informação, pois "vai além dos limites de apoio à escola, quando estimula essa clientela, ou seja, o educando, a uma frequente e permanente busca do conhecimento, mesmo não havendo mais qualquer vínculo com a escola" (ARAÚJO, 1985, p. 109).

Por não estar vinculada à educação formal, seu papel se faz por outras vertentes.
A biblioteca pública, sendo parte do complexo educacional, desempenha sua função educativa através da educação denominada não formal. Esta, por sua vez, é dissociada do sistema educacional regular; no entanto, lhe é inerente o papel de educar os indivíduos num processo permanente, estando relacionada com a aprendizagem não sistemática, adquirida através de meios de comunicação de massa e de órgãos sócio-culturais (ARAÚJO, 1985, p. 108).

Os manifestos de Caracas (1985) e UNESCO (1994) para as bibliotecas públicas já contemplavam em seus textos a importância do apoio à educação permanente nas bibliotecas públicas.

Apoiar a aprendizagem ao longo da vida em todos os níveis - formal e não-formal- dando ênfase na erradicação do analfabetismo e nos serviços para crianças, jovens, neoleitores e leitores impedidos física e socialmente (UNITED NATIONS EDUCATIONAL, SCIENTIFIC AND CULTURAL ORGANIZATION, 1985, p. 1, tradução nossa).

Apoiar a educação individual e a auto-formação, assim como a educação formal a todos os níveis (UNITED NATIONS EDUCATIONAL， SCIENTIFIC 


\section{AND CULTURAL ORGANIZATION, 1994, p.2).}

A função educativa também está vinculada ao desenvolvimento da competência informacional, à erradicação do analfabetismo e ao acesso no uso das novas tecnologias. Para Santa Maria (2011), a biblioteca deverá estar comprometida com "o ensino/aprendizagem de competências e habilidades relacionadas à recuperação da informação e à gestão das tecnologias, a fim de adquirir conhecimento e habilidade para transmiti-los" (SANTA MARIA, 2011, p. 59, tradução nossa).

\subsection{Acesso às tecnologias}

$\mathrm{Na}$ chamada Sociedade da Informação, na qual a globalização das informações e a dissolução das fronteiras geográficas possibilitaram um aumento na produção e velocidade da disseminação da informação, um desafio ainda se faz presente em países em desenvolvimento, como o Brasil: o acesso universal às tecnologias da informação. Para Araújo (1985, p. 109), as bibliotecas "devem participar do desenvolvimento da ciência e tecnologia, difundir os conhecimentos profissionais e favorecer a iniciativa criadora do homem".

Silvia Castrillon, bibliotecária colombiana, interessada e pesquisadora das bibliotecas públicas, aprofunda ainda mais na temática, propondo que o uso das tecnologias pode contribuir para a composição de redes que auxiliem na construção da cidadania.

As bibliotecas têm, então, outro papel importante a desempenhar: contribuir para recuperar a universalidade como valor, criar a consciência de que os benefícios da globalização não podem, de maneira alguma, limitar-se ao capital transacional. Para países pobres como os nossos, as tecnologias da informação, que permitem o estabelecimento de diferentes tipos de redes que se cruzam por todo o mundo, constituem, este caso, uma vantagem, especialmente porque os custos de comunicação são infinitamente menores (CASTRILLON, 2011, p. 81).

Os usuários encontram nas bibliotecas públicas um espaço para a apropriação das novas tecnologias, podendo se configurar como o único meio de acesso a computadores e a internet que algumas pessoas têm acesso (SANTA MARIA, 2011). Para Betancur (2002), a oferta de novas tecnologias é uma das missões da biblioteca pública.

Como impulsores deste serviço, nos acompanha a convicção de que devemos incentivar uma nova etapa no desenvolvimento das bibliotecas públicas, onde a tecnologia está a serviço do local; bancos de dados se alimentam de informação que incentive a participação e transformação das comunidades e os serviços e ações das bibliotecas públicas permitam a descoberta de novos indivíduos, capazes de encontrar e apropriar de informações que eles mesmos produzem e que o mundo produz (BETANCUR, 2002, p. 7, tradução nossa).

Para Lankes (2016):

Qualquer tecnologia precisa de algumas instruções básicas para o modo de usar. Não aprendemos a ler dormindo em cima de livros. Acesso não é o suficiente. Precisamos acreditar que nossas bibliotecas ajudem a preparar a comunidade a se engajar num aprendizado sempre ativo (LANKES, 2016).

\subsection{Conhecimento das comunidades}

Para a oferta de produtos e serviços que atendam às necessidades de seus usuários, é importante que a biblioteca conheça a comunidade em que está inserida, pois "um conhecimento mais sistemático do leitor ajuda o bibliotecário a satisfazer 
melhor suas necessidades, a aperfeiçoar os programas já existentes na biblioteca, a diversificar seus serviços aos usuários no tocante a programas culturais" (ARAÚJO, 1985, p. 115).

Somente a partir da investigação do que a população precisa, deseja e espera é que se será possível pensar as ações, ou seja, investigar a situação educacional, social e cultural da comunidade (ARAÚJO, 1985).

A medida que a biblioteca se vincula com o conjunto de seus usuários -reais e potenciais-, os conhece, interage e trabalha com eles de maneira individual e grupal, conta com melhores elementos para oferecer serviços adaptados às suas necessidades e exigências. Desta maneira pode propor atividades e produtos em horários apropriados e em lugares adequados (SANTA MARIA, 2011, p. 70, tradução nossa).

Cunha (2003, p. 69) chamou a atenção para a necessidade de se conhecer a "ecologia social em se insere a biblioteca pública", para que sejam criados produtos e serviços que atendam a todos os tipos de público.

A integração com a comunidade pressupõe conhecê-la para permitir o planejamento de ações e a criação de produtos e serviços adequados às necessidades dos usuários $\mathrm{da}$ biblioteca pública. Servir de mediadora entre a sociedade para a qual foi criada e o patrimônio cultural da humanidade, é papel do qual a biblioteca pública não pode abdicar. O processo de mediação é o reflexo de sua responsabilidade social com a formação e desenvolvimento da cidadania no espaço físico ou virtual de que se utilize para atender ao seu público (CUNHA, 2003, p. 70).

Nos últimos tempos temos visto o alargamento da tipologia de usuários atendidos pelas bibliotecas públicas. Estes grupos, específicos em faixa etária ou característica cultural, sempre existiram, mas provavelmente estavam invisíveis na sociedade e não eram contemplados nas políticas públicas. São eles os bebês, que já contam com acervos e serviços específicos, os ciganos, grupos quilombolas, indígenas, imigrantes e, mais recentemente, os refugiados.

$$
\begin{aligned}
& \text { Estudos indicam que o migrante } \\
& \text { que se utilizou da Biblioteca } \\
& \text { Pública de Nova York teve } \\
& \text { melhores condições para se adaptar } \\
& \text { à vida na grande cidade. Para } \\
& \text { propiciar uma melhoria de } \\
& \text { condições, obviamente, a biblioteca } \\
& \text { teve antecipadamente que } \\
& \text { diagnosticar as necessidades do } \\
& \text { migrante, correlacionar os } \\
& \text { problemas e planejar uma estrutura } \\
& \text { adequada e útil (SUAIDEN, 2008, } \\
& \text { p. 18). }
\end{aligned}
$$

Em 2015 a IFLA, atenta a atual situação dos refugiados na Europa, publicou um documento sobre a contribuição das bibliotecas públicas nos países que mais têm recebido essas pessoas. Neste documento constam experiências como a da Finlândia, que oferece panfletos em diversas línguas e também ajuda os refugiados na navegação pela internet. Já a França realizou um diagnóstico e implantou um serviço de um mediador poliglota presente na biblioteca três vezes por semana, com experiência para questões sociais, legais e administrativas. Ainda na França, foram criados workshops, com cerca de duas horas de duração, para trocas de experiências e conhecimento uns dos outros. Há também a exibição de filmes em francês, com legenda em francês para os que não dominam a língua poderem treiná-la (INTERNATIONAL FEDERATION OF LIBRARY ASSOCIATIONS AND INSTITUTIONS, 2015). A importância de conhecer a comunidade onde atua torna-se primordial para a oferta de serviços de qualidade.

O bibliotecário deve reconhecer que entre os diferentes tipos de visitantes ou usuários da biblioteca, estão também as pessoas que 
sofreram ou fizeram parte de circunstâncias diferentes associadas com o conflito armado ou violência. Estas pessoas em processo de reintegração social, fazendo parte da comunidade, podem encontrar na biblioteca pública não só um lugar de reparação e re-socialização através da reconstrução da memória e atividades para crianças, jovens e adultos que se insiram em projetos de formação como leitores e escritores, mas também um centro de informação e orientação para ajudá-los a compreender os seus direitos e legislação e as legislações e disposições adotadas para restaurar os direitos das vítimas do conflito armado no país (SANTA MARIA, 2011, p. 20, tradução nossa).

Como organismo vivo, influenciado pelas mudanças sociais e temporais, as bibliotecas públicas têm procurado adaptar sua atuação com o intuito de atender a todos os tipos de público, em suas diversas demandas.

\subsection{Interlocução com a comunidade}

A construção da cidadania, o fortalecimento da democracia e o desenvolvimento pessoal encontram solo fértil nas bibliotecas públicas, que possibilitam, por meio da informação e da cultura, acesso a diversidade de visões e opiniões. Mas para que, efetivamente, possa desenvolver esse papel, é preciso que haja um reconhecimento da população com relação à instituição e essa se dará por meio da interlocução com a comunidade.

Portanto, à medida que a biblioteca pública se vincular adequadamente com a comunidade, ela passará a ser o caminho que possibilitará a participação efetiva na sociedade da informação. Isso é de extraordinária importância em um país onde a desinformação atinge altas proporções, e, sem essa oportunidade, milhares de pessoas jamais terão oportunidade de entender e de ter noção dos seus direitos e deveres em uma sociedade globalizada, pois o acesso à informação, nos novos tempos, significa o investimento adequado para diminuir as desigualdades sociais e as formas de dominação que foram dominantes na história contemporânea (SUAIDEN, 2000, p. 60).

Essa interlocução se faz com os usuários individuais, mas também com outras instituições, grupos, organizações de todas as áreas. A partir do fortalecimento destas relações é que será possível construir um caminho de atuação que faça diferença na comunidade onde está inserida a biblioteca pública.

A atividade de uma biblioteca pública, como qualquer outro serviço social, concentra-se nas relações que estabelece com sua comunidade. Isto inclui indivíduos, grupos organizados e instituições com quem trabalham e interagem constantemente. A ligação e o compromisso com esferas educacionais, culturais, econômicas e políticas da comunidade fazem com que a biblioteca seja chamada de uma instituição social (SANTA MARIA, 2011, p. 70, tradução nossa).

Tal fortalecimento da relação com a comunidade parece ser a possibilidade de sucesso no futuro das bibliotecas, como destaca Suaiden (2008):

Os especialistas que trabalham com a área de tendências em bibliotecas públicas afirmam frequentemente que o futuro e o sucesso da instituição dependem basicamente da sua capacidade de se interagir com a comunidade. Assim sendo, os estudos sobre a comunidade, o trabalho com as lideranças comunitárias e o diagnóstico aplicado às necessidades de informação são instrumentos 
fundamentais com as quais a biblioteca pública pode contar para se vincular e até melhorar os níveis de educação e cultural da comunidade (SUAIDEN, 2008, p.12).

A convocação de Lankes (2016) para se criar bibliotecas melhores passa essencialmente pela interlocução e participação da comunidade na biblioteca pública, pois os usuários "não são consumidores passivos de conteúdo da biblioteca, eles são a própria razão da biblioteca existir".

\subsection{Lugar do encontro}

Para além de suprir demandas informacionais, as bibliotecas públicas, especialmente as localizadas em pequenas comunidades, tornam-se lugares de encontro e socialização da comunidade, nomeadas pela IFLA como "sala de visita".

A biblioteca pública desempenha importante papel como espaço público de encontro. Isso é particularmente importante em comunidades onde há poucos lugares de encontro. Ela é às vezes chamada de "sala de visitas da comunidade". O uso da biblioteca para pesquisa, ensino e lazer aproxima as pessoas graças a contatos informais, proporcionando uma experiência social positiva (INTERNATIONAL FEDERATION OF LIBRARY ASSOCIATIONS AND INSTITUTIONS, 2012, p.11).

Por sua característica democrática, o livre acesso oferece a possibilidade de transitar por um espaço de socialização, em um tempo de intervalo entre a escola e a casa para os estudantes (PÉREZ IGLESIAS, 1999), favorecendo o compartilhamento e proporcionando a construção de uma sociedade mais igualitária. Desta forma, Pérez Iglesias (1999) salienta a necessidade das bibliotecas estarem afinadas às demandas da comunidade para poderem atuar neste sentido.

As bibliotecas públicas, enquanto instituições flexíveis e adaptadas às necessidades de sua comunidade, tornam-se parte ativa na construção de uma sociedade cívica. O fato de que elas são locais abertos e de que se pode entrar sem necessidade de permissão, as torna em locais privilegiados de socialização. Para muitas crianças, ter uma carteira de biblioteca é a primeira maneira de ser reconhecidos como cidadãos individualizados (PÉREZ IGLESIAS, 1999, p. 25, tradução nossa).

Ainda que para alguns estudantes a biblioteca pública se torne prioritariamente um local para realização da tarefa escolar, o encontro que ali se faz com outras pessoas, com muitas informações em diversos suportes, e até consigo mesmo por meio da leitura, torna esta experiência de socialização, para muitos, uma das poucas oportunidades no dia a dia.
A biblioteca não é apenas um lugar para fazer lição de casa. É um lugar para conhecer outras pessoas e um lugar para reunir-se consigo mesmo através da leitura, com autores vivos e mortos, com obras de arte, com o conhecimento científico e com informação de qualquer tipo. A biblioteca é o lugar para formar leitores, para compartilhar leituras, para crescer como cidadãos. Hoje, graças à tecnologia de informação e comunicação, também é um lugar onde é possível se apropriar de conteúdo adequado, participar em redes sociais, culturais ou de conhecimento (SANTA MARIA, 2011, p. 10, tradução nossa).

A biblioteca pública também possui como característica ser um ambiente físico seguro. Para Lankes (2016) essa "segurança pode ter diferentes vieses: os dois que as bibliotecas mais se preocupam é o da segurança física e o da segurança intelectual. 
Bibliotecas muitas vezes são citadas como locais seguros".

Uma biblioteca pública do município de Taguatinga, Distrito Federal, tem relatos sobre a segurança que seus diferentes usuários sentem na instituição. Desde um pai e uma filha que aguardavam o fim da aula da mãe no período noturno até um homem em situação de rua que entrava às oito da manhã e só saía às vinte duas horas, buscavam na biblioteca um ambiente seguro e com possibilidade de acesso à informação e à leitura ${ }^{5}$.

Desenha-se assim uma nova maneira de pensar produtos e serviços para as bibliotecas públicas, que não podem fugir à premissa de atender seu público e suas demandas, sejam elas quais forem.

\subsection{Construção da cidadania}

O conceito de cidadania, segundo um dos autores mais representativos da área (MARSHALL, 1967) possui três dimensões: a civil, a política e a social. Os direitos civis, relacionados à liberdade individual, o político, que se relaciona ao exercício de eleitor e os sociais, que têm a ver com o bem-estar econômico e segurança e com a possibilidade de participar da vida social. Segundo Mangue (2011, p. 41) cidadania é "uma ação crucial para se promover a justiça social e o bem comum, especialmente no contexto atual em que interesses meramente econômicos primam por turvar a visão e compreensão dos cidadãos".

$\mathrm{O}$ acesso à informação parece se configurar como um passo essencial para a construção da cidadania. Neste sentido, Mangue salienta que:

É fundamental que todos os cidadãos sejam informados e munidos de conhecimentos acerca, não só dos mecanismos de participação disponíveis numa democracia representativa (que

${ }^{5}$ Informações disponíveis em:

$<$ http://ultimosegundo.ig.com.br/educacao/alemdos-livros-as-multiplas-funcoes-de-uma-bibliotecapublica/n1597369382299.html>. Acesso em: 01 maio 2017. resumem-se em quase sua totalidade à escolha dos representantes), como também acerca das novas possibilidades que têm surgido como conquista da sociedade civil organizada no sentido de se implementar uma democracia mais participativa e deliberativa que atue numa perspectiva mais abrangente em termos de garantia de direito (MANGUE, 2011, p. 41).

Além das informações essenciais para a sobrevivência, como é o caso das informações utilitárias discutidas anteriormente, a construção da cidadania também ocorre pelo conhecimento de si mesmo, possibilitando o desenvolvimento de valores importantes para a convivência em comunidade.

Os livros e recursos que oferecem bibliotecas públicas podem reduzir a sensação de solidão, valorizar a diferença e fazer que a vida seja digna de ser vivida. Além disso, todos estes documentos estão disponíveis sem juízos de valor sem restrições (PÉREZ IGLESIAS, 1999, p. 27, tradução nossa).

Castrillon (2011) convoca as bibliotecas públicas a atuarem como espaços contra a exclusão social, tendo em vista seu caráter diverso, tanto de público, como de informações disponíveis.

Um país requer bibliotecas que possam ir mais além desse plano mínimo de trabalho. Bibliotecas que, em primeiro lugar, se convertam em meios contra a exclusão social, isto é, que se constituam em espaços para o encontro, para o debate sobre os temas que dizem respeito a maiorias e minorias; bibliotecas onde crianças, jovens e adultos de todas as condições, leitores e não leitores, escolares e não escolares, encontrem respostas a seus problemas e interesses e lhes sejam abertas a novas perspectivas (CASTRILLON, 2011, p. 36). 
Segundo a autora, as bibliotecas públicas devem promover oportunidades de debate sobre temas que são de interesse da comunidade e que "provoquem a reflexão, a crítica e o questionamento, e sejam instrumentos capazes de apoiar, sem qualquer tipo de pressão, a tomada de consciência e a real formação cívica e cidadã" (CASTRILLON, 2011, p.36).

Suaiden (2002) nos alerta para outro fator ainda mais grave que a desinformação, que é a manipulação das informações, causando graves consequências para a sociedade, sendo papel das bibliotecas preservarem a veracidade das informações disponibilizadas. As consequências podem ser não saber discernir, criticar e decidir em favor de seu próprio desenvolvimento, indicando que a exclusão social é também um processo de desinformação.

A desinformação não é apenas a falsa divulgação de propósito geral de propaganda. São ações calculadas tendo em vista atingir o objetivo. A desinformação não se limita apenas a dados políticos acessíveis às pessoas. A desinformação de alto nível falsifica informação especializada e técnica de relevância incomparavelmente maior (SUAIDEN, 2002, p. 336, tradução nossa).

Para o encerramento deste item, parece pertinente citar Betancur (2002), que dimensiona a grandeza do papel das bibliotecas públicas em todas as suas práticas, reconhecendo as facetas que elas devem desempenhar para a "construção de um projeto de futuro" em sociedades democráticas.

A partir desta perspectiva, o compromisso da biblioteca pública para o desenvolvimento local é baseada na biblioteca pública que é uma instituição que a partir de suas práticas culturais, sociais e educacionais têm uma forte nuance política que normalmente não é reconhecida e exercida pelo bibliotecário. Esta nuance política que eu quero dizer, pode ou deve gerar contribuições das bibliotecas públicas para os processos de participação cidadã na comunidade; a formação de indivíduos e grupos, de atitudes positivas para com o coletivo, o público, o comum; a capacidade de motivar as pessoas a transformar o seu papel de espectadores e se tornar atores no processo de desenvolvimento de sua comunidade, de projetos comunitários que coordenam os recursos e atores em um dado território que exige, mais do que nunca, que a biblioteca ofereça à comunidade uma informação adequada e relevante para projetar o futuro (BETANCUR, 2002, p. 4, tradução nossa).

\subsection{Perfil do bibliotecário}

Parece difícil pensar em uma biblioteca pública atuando como instituição social, com vistas à construção da cidadania e auxiliando na vida democrática das sociedades, se não contar com um profissional capacitado para pensar e executar todas estas ações. Dessa forma, o perfil do bibliotecário que atua em uma biblioteca pública deverá contemplar características que perpassem pela técnica biblioteconômica de organização da informação, mas também é preciso um vasto conhecimento de estudos de usuários, das políticas públicas e também uma simpatia para as causas sociais, pois "é com espírito de socialização que o bibliotecário desempenhará o seu papel de agente social" (ARAÚJO, 1985, p. 120).

A única forma de obter bibliotecas que cumpram esses novos desafios é contar com um bibliotecário que se apresente como um intelectual capaz de assumir um compromisso ético e político com seu país e com a sociedade, e que responda pela administração de um instrumento público, que, por sua vez, deva estar a serviço de um mundo mais justo para todos os cidadãos (CASTRILLON, 2011, p. 39). 
A conexão do bibliotecário com seus usuários se faz pelo reconhecimento de suas necessidades de leitura e informação, mas também de suas necessidades sociais, além de suas potencialidades, pois ele "poderá, desta forma, melhor servir aos indivíduos e aos grupos de pessoas nos seus diversos interesses: culturais, educacionais ou profissionais" (ARAÚJO, 1985, p.118).

$\mathrm{O}$ atendimento ao usuário que busca a biblioteca e a organização do espaço não devem ser as únicas tarefas deste profissional.

O seu papel vai muito além: conhecer pessoas de sua comunidade, fazer esforços para inserir o projeto de biblioteca em planos de desenvolvimento local, propor atividades em torno de leitura e informação, promover, conseguir recursos para melhorar a tecnologia e instituições relacionadas e se relacionar com os grupos comunitários, participar de seus projetos; também conhecer a coleção, explorar, saber com que materiais se pode contar, de que se tratam, onde estão, o que falta, o que é mais utilizado e que é necessário para adquirir (SANTA MARIA, 2011, p. 24, tradução nossa).

O desenvolvimento dos conhecimentos e habilidades para a atuação nas bibliotecas públicas inicia na formação acadêmica, mas se faz necessário avançar em sua formação continuada e atualização permanente.

Pensar no desempenho do profissional da informação bibliotecário significa refletir na sua formação básica e continuada, visto que a formação e o desempenho são fatores interdependentes. $\mathrm{O}$ bibliotecário da biblioteca pública contemporânea está à procura de uma nova identidade em razão das profundas mudanças na sociedade, que vêm determinando a necessidade de inovação de produtos e serviços, novos padrões, outras estratégias para satisfazer às demandas de um público que clama por cidadania, redução das desigualdades sociais (CUNHA, 2003, p. 70).

Lankes (2016) entende que a comunidade se constitui como centro da biblioteca, e que ela deve trabalhar para atender esta comunidade.

Comunidades têm aspirações e sonhos, a biblioteca pode ajudar a realizar estes sonhos. Comunidades também se deparam com problemas e desafios e a biblioteca também deve estar lá para ajudar [...]. Elas devem ser espaços para criação e compartilhamento de conhecimento, não somente um espaço cheio de livros. Sabemos que a função de uma biblioteca deve transcender as quatro paredes. As comunidades devem acreditar que as bibliotecas podem cada vez mais criar serviços que as motivem (LANKES, 2016).

\section{REFLEXÕES SOBRE A FUNÇÃO SOCIAL DA BIBLIOTECA PÚBLICA}

Todos os tópicos acima discutidos nos levam a pensar, justamente, na dimensão social da biblioteca pública como força constituinte de sua atuação. Para Betancur (2002), as dimensões da leitura, da informação e da cultura formam a essência que justifica sua existência.

Para abordar o papel social das bibliotecas públicas como instituições que se dizem democráticas, deve-se notar que, das muitas funções que são internacionalmente disseminadas, estão três razões do trabalho da biblioteca pública: em primeiro lugar promover a leitura como uma prática social e cultural. Em segundo, garantir o acesso a informação internacional, nacional e local em várias mídias e formatos, com uma visão democrática e justa; e, em terceiro lugar, a divulgação de manifestações artísticas e culturais, 
contribuindo para a construção de uma cultura própria com sentido universal (BETANCUR, 2002, p. 3, tradução nossa).

As poucas e descontínuas políticas públicas brasileiras específicas para a área das bibliotecas (PAIVA, 2008), o pouco reconhecimento das administrações locais sobre sua relevância e a falta de legitimação da população advinda destes fatores (FERNANDEZ, 2016) acarretou no Brasil uma situação precária para as bibliotecas públicas. Elas se tornaram, na maioria dos casos, salas cheias de livros, sem nenhuma conexão com seu entorno e com a realidade que atuam, sendo apenas portas abertas para alguns usuários acidentais.

A biblioteca pública como instituição social parece ter um grande desafio ao pensar em acervo, serviços, interlocução com a comunidade, acesso às tecnologias, entre outros.

Para Tello (2013), este "perfil sociológico" se apresenta de três maneiras.

A premissa referente à biblioteca pública como uma instituição social apresenta um valioso perfil sociológico, que pode ser resumido da seguinte forma: 1) adota ideologicamente a estrutura de uma organização social que nasceu com a biblioteca moderna não apenas como um recurso, mas também como uma solução reguladora para a seleção, coleta, organização e implementação para um amplo uso social da informação; 2) assegurou a sobrevivência de uma sociedade por ter se tornado a principal agência para que a informação seja facilmente acessível para os membros da sociedade, e 3) é o legado cultural mais significativo para sociedade (TELLO, 2013, p. 161, tradução nossa).

\section{CONSIDERAÇÕES FINAIS}

Todos os pontos discutidos ao longo deste artigo servem para refletirmos sobre a importância inegável das bibliotecas públicas e para superar qualquer dúvida a respeito da continuidade destas instituições.

Apesar de um número enorme de bibliotecas ainda resistirem em uma situação agonizante, já presenciamos exemplos de bibliotecas que conseguiram mudar o rumo e seguir em um caminho onde realmente elas se fazem essenciais. Mas é importante não deixarmos de mencionar que essas bibliotecas só conseguem realizar um trabalho de relevância porque contam com bibliotecários e profissionais entusiasmados, motivados e curiosos. São agentes que buscam participar da elaboração da política de seus municípios, estados e nação, entendendo que sua experiência é fundamental para a construção e estabelecimento de políticas públicas e diretrizes de atuação. Consequentemente, criam laços com a comunidade e fortalecem seu papel, empoderando seus usuários na construção de bibliotecas que realmente façam a diferença onde estão inseridas.

Longe de querer perpetuar uma visão romântica que vez por outra aparece no discurso sobre as bibliotecas públicas, este artigo propõe apenas que pensemos (bibliotecários e militantes das bibliotecas públicas) além do mínimo que é oferecido e busquemos novos modos de pensar e fazer, entendendo que as pessoas (e suas demandas, necessidades, interesses e desejos) serão sempre a dimensão essencial da vida em sociedade.

\title{
ESSENTIAL DIMENSIONS OF PUBLIC LIBRARIES
}

\begin{abstract}
Based on a theoretical reflection on the social role of public libraries, this article presents twelve essential dimensions for thinking about its performance in the communities that they are inserted, demonstrating its relevance for democratic and citizen participation. It also discusses the importance of the work of the librarian as a fundamental agent for the interaction with the community, for the contact with reading and information and consequently for the establishment of personal, professional and affective relationships in the library.
\end{abstract}


Keywords

Public libraries. Social role. Librarian professional performance.

Artigo recebido em 17/04/2018 e aceito para publicação em 26/04/2018

\section{REFERÊNCIAS}

ARAÚJO, W. T. A biblioteca pública e o compromisso social do bibliotecário. Revista da Escola de Biblioteconomia da UFMG, Belo Horizonte, v. 14, n.1, p. 106122, mar. 1985.

BERNARDINO, M. C. R.; SUAIDEN, E. J. O papel social da biblioteca pública na interação entre a informação e o conhecimento no contexto da ciência da informação. Perspectivas em Ciência da Informação, Belo Horizonte, v.16, n.4, p.29-41, out./dez. 2011.

BETANCUR, A. M. La biblioteca pública em la perspectiva del desarrollo local: uma estratégia para la democracia. In: IFLA Council and General Conference, 68, 2002, Glasgow. Anais eletrônicos... Glasgow: IFLA, 2002. Disponível em: $<$ https://archive.ifla.org/IV/ifla68/papers/ 124-084s.pdf >. Acesso em: 02 abr. 2017.

CASTRILLÓN, S. O direito de ler e de escrever. São Paulo: Pulo do Gato, 2011.

CESARINO, M. A. N. Bibliotecas públicas municipais: orientações básicas. Belo Horizonte: Secretaria de Estado da Cultura de Minas Gerais, Superintendência de Bibliotecas Públicas, 2007.

CUNHA, V. A. A biblioteca pública no cenário da sociedade da informação. BIBLIOS, Brasília, Ano 4, n. 15, abr./jun. 2003.

DUMONT, L. M. M. Contexto, leitura e subjetividade. Transinformação, Campinas, v. 13, n. 1, p.43-47, jan./jun. 2001.

FERNANDEZ, C. (Coord.). Bibliotecas públicas: um equipamento cultural para $\mathrm{O}$ desenvolvimento local. Recife: Centro de Desenvolvimento e Cidadania, 2016.
INTERNATIONAL FEDERATION OF LIBRARY ASSOCIATIONS AND INSTITUTIONS. Acesso e oportunidades para todos: como as bibliotecas contribuem para a agenda de 2030 das Nações Unidas. Disponível em: $<$ https://www.ifla.org/files/assets/hq/topi cs/libraries-

development/documents/access-andopportunity-for-all-es.pdf $>$. Acesso em: 02 abr. 2017.

INTERNATIONAL FEDERATION OF LIBRARY ASSOCIATIONS AND INSTITUTIONS. Diretrizes da IFLA. [S. 1.]:

IFLA, 2012.

INTERNATIONAL FEDERATION OF LIBRARY ASSOCIATIONS AND INSTITUTIONS. Responding! Públic libraries and refugees. 2015. Disponível em: $<$ https://www.ifla.org/files/assets/publiclibraries/publications/library_service_to_refugees. pdf>. Acesso em: 02 abr. 2017.

LANKES, D. Expect more: melhores bibliotecas para um mundo complexo. [S.1.]: FEBAB, 2016. Disponível em:< https://davidlankes.org/newlibrarianship/expect-more-demandingbetter-libraries-for-todays-complex-world/1the-arab-spring-expect-the-exceptional/ $>$. Acesso em: 11 jul. 2017.

MACHADO, E. C.; ELIAS JUNIOR, A. C.; ACHILLES, D. A biblioteca pública no espaço público: estratégias de mobilização cultural e atuação sócio-política do bibliotecário. Perspectivas em Ciência da Informação, Belo Horizonte, v.14, número especial, p. 115-127, out./dez. 2014.

MANGUE, D. C. S. Organizações de defesa do cidadão. In: MOURA, M. A. (Org.). Cultura informacional e liderança comunitá- 
ria: concepções e práticas. Belo Horizonte: UFMG/PROEX, p. 39-44, 2011.

MARSHALL, T. H. Cidadania, classe social e status. Rio de Janeiro: Zahar, 1967. MILANESI, Luís. Biblioteca pública: do século XIX para o XXI. Revista USP, São Paulo, n. 97, p. 59-70, mar./abr./maio, 2013.

PAIVA, M. A. M. Bibliotecas públicas: políticas do estado brasileiro de 1990 a 2006. 2008. 144 f. Dissertação (Mestrado em Ciência da Informação) - Universidade Federal de Minas Gerais, Escola de Ciência da Informação, Belo Horizonte, 2008.

PÉREZ IGLESIAS, J. Las bibliotecas como bien público: el fator humano. Educación y biblioteca, Madrid, n. 97, p. 25-27, 1999.

RANGANATHAN, S. R. Cinco leis da Biblioteconomia. Brasília: Briquet de Lemos Livros, 2009.

SANTA MARIA, G. M. R. La biblioteca pública que queremos. Colômbia: Ministério da Cultura, 2011.

SILVEIRA, F. J. N.; REIS, A. S. Biblioteca pública como lugar de práticas culturais: uma discussão sócio-histórica. Informação \& Sociedade, João Pessoa, v.21, n.1, p. 37-54, jan./abr. 2011.

SUAIDEN, E. J. A biblioteca pública no contexto da sociedade da informação. Ciência da Informação, Brasília, v. 29, n. 2, p. 52-60, maio/ago. 2000.

Biblioteca pública e informação a comunidade. São Paulo: Global, 2008.
El impacto social de las bibliotecas públicas. Anales de Documentación, Murcia (Esp.), n. 5, p. 333-344, 2002.

TELLO, F. M. Bibliotecas y sociedade: al paradigma social de la biblioteca pública. Investigacion bibliotecológica, Cidade do México, v.27, n.61, p.157-173, sep./dic., 2013.

UNITED NATIONS EDUCATIONAL, SCIENTIFIC AND CULTURAL ORGANIZATION. Declaración de Caracas sobre la biblioteca pública como factor de desarrollo e instrumento de cambio en América Latina y el Caribe. Caracas, 1985. Disponível em:

$<$ http://snbp.culturadi:gital.br/manifestos/ manifesto-de-caracas-sobre-bibliotecaspublicas/>. Acesso em: 02 abr. 2017.

UNITED NATIONS EDUCATIONAL, SCIENTIFIC AND CULTURAL ORGANIZATION. Manifesto da Unesco para bibliotecas públicas. 1994. Disponível em:

<http://www.ifla.org/VII/s8/unesco/port. htm>. Acesso em: 15 ago. 2016.

VERGUEIRO, W. Seleção de materiais de informação: princípios e técnicas. Brasília: Briquet de Lemos, 2010.

VIEIRA, L. A. Informação utilitária: definição, uso e perspectiva. In: MOURA, Maria Aparecida (Org.). Cultura informacional e liderança comunitária: concepções e práticas. Belo Horizonte: UFMG/PROEX, p. 71-74. 2011. 